\title{
Addition of platelet concentrate to Dermo-Epidermal Skin Graft in deep burn trauma reduces scarring and need for revision surgeries
}

\author{
Vaclav Prochazka ${ }^{a}$, Hana Klosova ${ }^{b}$, Jiri Stetinsky ${ }^{b}$, Jaromir Gumulec, Katerina Vitkova ${ }^{d}$, Dana Salounova ${ }^{e}$, Jana Dvorackova ${ }^{f}$, \\ Hana Bielnikova ${ }^{f}$, Petr Klement ${ }^{\text {gt }}$, Veronika Levakova ${ }^{\text {}}$, Tomas Ocelkai, Lubomir Pavliskaj, Pavel Kovanick, \\ Giannoula Lakka Klement ${ }^{\mathrm{lm}, \mathrm{n}}$
}

\begin{abstract}
Backround. Deep skin burn injuries, especially those on the face, hands, feet, genitalia and perineum represent significant therapeutic challenges. Autologous dermo-epidermal skin grafts (DESG) have become standard of care for treating deep burns. Additionally, human autologous thrombin activated autologous platelet concentrate (APC) has gained acceptance in the setting of wounds. While each of these interventions has been independently shown to accelerate healing, the combination of the two has never been evaluated. We hypothesized that the addition of platelets (source of growth factors and inhibitors necessary for tissue repair) to the DESG (source of progenitor cells and of tissue proteases necessary for spatial and temporal control of growth regulators released from platelets) would create the optimal environment for the reciprocal interaction of cells within the healing tissues.

Methods. We used clinical examination (digital photography), standardised scales for evaluating pain and scarring, in combination with blood perfusion (laser Doppler imaging), as well as molecular and laboratory analyses.

Results. We show for the first time that the combination of APC and DESG leads to earlier relief of pain, and decreased use of analgesics, antipruritics and orthotic devices. Most importantly, this treatment is associated with earlier discharges from hospital and significant cost savings.

Conclusions. Our findings indicate that DESG engraftment is facilitated by the local addition of platelets and by systemic thrombocytosis. This local interaction leads to the physiological revascularization at 1-3 months. We observed significant elevation of circulating platelets in early stages of engraftment (1-7 days), which normalized over the subsequent 7 and 90 days.
\end{abstract}

Key word: deep burn trauma, dermo-epidermal skin graft, surgical debridement, necrectomy, autologous platelet concentrate (APC), human autologous thrombin (HAT), scarring, laser doppler perfusion imaging (LDPI), gnostic analysis

Received: January 31, 2013; Accepted with revision: September 13, 2013; Available online September 27, 2013 http://dx.doi.org/10.5507/bp.2013.070

anstitute of Radiodiagnostic and Vice-President for Science and Research, University Hospital Ostrava, Czech Republic

${ }^{b}$ Burn centre, University Hospital Ostrava

'Institute of Clinical Hematology, University Hospital Ostrava

${ }^{d}$ Department of Vice-President for Science and Research, University Hospital Ostrava

${ }^{e}$ Department of Mathematical Methods in Economy, VSB-Technical University of Ostrava

fInstitute of Pathology, University Hospital Ostrava

${ }^{9}$ Vice-rector for External Affairs, VSB-Technical University of Ostrava

${ }^{h}$ Complex Oncologic centre, P\&R Lab, Novy Jicin

iInstitute of Public Health Ostrava, Partyzanske nam. 7, 70200 Ostrava,

jE\&H services, Inc., Navratilova 1421/11, Prague

${ }^{k}$ Retired scientist from the Czech Academy of Sciences

'Pediatric Hematology Oncology, Floating Hospital for Children at Tufts Medical Center, Boston, MA, USA

${ }^{m}$ Center of Cancer System Biology, Steward St. Elizabeth Health Center, Boston, MA, USA

"Tufts University School of Medicine, Boston, MA, USA

Corresponding author: Vaclav Prochazka, e-mail:angio@vol.cz

\section{INTRODUCTION}

Despite significant recent advances in wound care, therapeutic outcomes are often functionally, psychologically and cosmetically unacceptable. No solutions have been found to address the prevalence of severe scar hypertrophy, joint contractures, peripheral neuropathy, or systemic temperature dysregulation. At present, standard of care for treating deep burns consists of surgically ex- cising necrotic tissue (necrectomy), followed by dermoepidermal skin autografting.

The use of autologous platelet concentrates (APC) is well established ${ }^{1-5}$, and there is ample evidence that platelets facilitate various wound healing processes such as chemotaxis $^{6}$, recruitment of progenitor cells ${ }^{7}$, proliferation ${ }^{8}$, angiogenesis ${ }^{9}$, and inflammation ${ }^{10}$. We have previously published evidence that APC is beneficial in the treatment of chronic ischemic ulcers, and can lead to limb salvage 
in the most severe cases ${ }^{1}$. Evidence suggests that platelets actively and selectively sequester angiogenesis regulators ${ }^{11}$, and differentially release inhibitors and stimulators of angiogenesis $^{12,13}$. This differential release of stimulators and inhibitors of angiogenesis from platelets is conditional on a direct platelet/stroma interaction. Similarly, the benefits of DESG are well-documented, even though no explanation is available for the excessive cicatrization that often accompanies the use of DESG. It can be thus surmised based on emerging evidence that a direct reciprocal interaction of platelets and wound matrix must occur for optimal tissue regeneration ${ }^{14,15}$. Moreover, we hypothesize that the combination therapy of DESG and activated platelets may be more efficacious than either individual modality. Thus, the goal of this study was to evaluate, whether the combination of DESG (a surrogate for cellular therapy) and platelet concentrate (a surrogate inflammatory modulator) leads to development of stable, non-hypertrophic scarring; thereby, preventing pain and shortening hospitalization.

Evidence suggests that platelets actively and selectively sequester angiogenesis regulators ${ }^{11}$, and differentially release inhibitors and stimulators of angiogenesis ${ }^{12,13}$.We explored the molecular determinants of this interaction in the present study by directly correlating physiological (laser Doppler perfusion imaging), clinical (pain scale, Vancouver scar scale and ratio of healed/total grafted area), and morphological (immunohistochemistry and epithelialization) evaluations to specific clinical endpoints such as time to wound closure, frequency of infections, inflammation and scarring.

\section{MATERIALS AND METHODS}

\section{Selection of subjects and determination of areas to be grafted}

Consecutive patients with second or third degree burns seen at the Burn Centre of University Hospital Ostrava, between January 2009 and November 2010, were approached for participation in the study. The study was registered on clinicaltrials.org under the number NCT01383187, and was approved by the Institutional Review Board (IRB-No16/b2008 on April 30 $\left.{ }^{\text {th }}, 2008\right)$. All 18 patients who agreed to participate ( 9 men, 9 women) consented according to institutional guidelines, and received standard therapy, which included surgical excision of devitalised tissue, dermo-epidermal skin auto transplantation, analgesia, and wound care. The additional local application of APC to the DESG before wound application was tested for improvement over standard care.

The timing of surgery was based on real or expected clinical progression. Determination of surgical management necessity was based on daily clinical examination as well as laser Doppler perfusion imaging (LDPI) every second day for up to 7 days. Any IIb-degree burn traumas, which were not expected to heal within 21 days, and all third degree burns, were grafted with DESG.

\section{Surgical Procedure}

A radical excision of nonviable tissue was done just prior to grafting using tangential or fascial excision of necrotic tissues. DESG (split thickness skin grafts) were obtained using electric dermatome (Nouvag, Switzerland or Aesculap, Germany) from the thigh. After positioning of the DESG, it was spray-coated with APC and human autologous thrombin using a SmartJet applicator Harvest Technologies Inc, Plymouth, USA). After 20-30 seconds to allow gelling, the area was covered with Surfasoft foil (Taureon, Netherlands) and the dressing was fixed with disposable skin staplers at the margins. To prevent drying of the foil, a layer of gauze moistened with saline was applied before the final top layer of elastic roller bandage (Panep, Czech Republic).

\section{Preparation of the APC}

The APC was prepared using the Harvest SmartPRep Platelet Concentrate System [Harvest Technologies, Plymouth, MA, USA] as described previously ${ }^{16}$.

Preparation of autologous thrombin: briefly, peripheral venous blood was obtained under aseptic conditions by venipuncture just prior to the surgery. The first $9 \mathrm{~mL}$ of venous blood collected into $1 \mathrm{~mL}$ ACD-A anticoagulant [Harvest Technologies] primed syringe and allowed to stand for $45 \mathrm{~min}$ at room temperature. This was centrifuged at 1000 RPM for $15 \mathrm{~min}$, filtered using the set provided by Harvest technologies. During the $45 \mathrm{~min}$ incubation, $60 \mathrm{~mL}$ of venous blood was collected for preparation of APC. The $60 \mathrm{~mL}$ of venous blood along with the $6 \mathrm{~mL}$ of ACD-A (1:10 dilution) was put into the separator chamber and the gradient density centrifugation using the Harvest Technology System for $15 \mathrm{~min}$ at 1000 RPM was provided. After finishing the process of centrifugation we kept at disposal the $3 \mathrm{~mL}$ of autologous thrombin and $10 \mathrm{~mL}$ of aoutologous platelet rich plasma. On average, $10 \mathrm{~mL}$ of APC can cover $\sim 4 \%$ of the total body surface area. The direct spray application of the APC and the autologous thrombin was done using the SmartJet applicator [Harvest Technologies, Plymuth, MA, USA].

\section{Hematological, biochemical, and cytokine analyses}

Hemoglobin concentration, a full white blood cell differential, platelets count, mean platelet volume, platelets distribution width and immature platelets fraction were evaluated in whole blood, platelet rich plasma and platelets-depleted plasma prior to surgery, and at 7, 14, and 90 days (Table 3 ). Prothrombin time, activated partial thromboplastin time, thrombin time, and fibrinogen were measured on a SYSMEX CA 7000 automated analyzer prior to surgery, and at 7, 14 and 90 days. Measured hematological values were compared to clinical ranges of normal values. Biochemical analysis such as liver function tests (ALT, AST, GGT) and inflammatory indexes (C-reactive protein), and analysis of cytokines by means of ELISA (BioVendor - Laboratorni medicina, Czech Republic) were performed according to standard procedures supplied by the manufacturer. 


\section{Histopathology analysis}

Burn eschar, DESG alone, and DESG/APC specimens were fixed by immersing in $10 \%$ formalin and processed in the Clinical Pathology lab. After alcohol-xylene dehydration and automated paraffin embedding, 2-4 $\mu \mathrm{m}$ sections were cut and mounted on a glass microscope slides before staining with hematoxylin/eosin. The DESG and DESG/APC specimens were also stained by immunohistochemistry for PDGF, VEGF, bFGF, and SDF1, using monoclonal anti-PDGF, (BioGenex, San Ramnon, USA), polyclonal rabbit anti-VEGF (DakoCytomation), polyclonal mouse anti-PDGF-B (BioGenex) with secondary chromophore staining red (DakoCytomation) and brown (EXBIO). A senior clinical pathologist completed the final pathological examination in a blinded fashion.

\section{Laser Doppler perfusion Imaging (LDPI)}

A Perimed PIM3 laser Doppler perfusion imager was used to assess tissue perfusion in the burn region. The method employs color-coded mapping of skin perfusion using a laser beam to detect velocity and volume of red blood cells ${ }^{17}$, and the evaluations were made pre-operatively, every second day for 2 weeks post operatively, and then at 1, 3, 6, 12 months.

\section{Graft Evaluation}

Viability: A visual analogue scale for graft viability was developed at our centre and consisted of the following scores: i) graft color (scale 0-3), where $0=$ pink, $1=$ pale, $2=$ livid (dark purplish, hyperperfused, +/- secretions), $3=$ necrotic; graft fixation to wound bed (scale $0-2$ ), where $0=$ entire graft is fixed, $1=$ areas of incomplete fixation, $2=$ total lack of fixation; secretions (scale $0-3$ ), where $0=$ no secretion through the fenestrations, $1=$ serous secretions, $2=$ seropurulent secretions, $3=$ purulent secretions. The evaluations were made every second day for 2 weeks post operatively, and the best total score was 0 .

The Vancouver Scar Score Scale has been validated recently and uses pigmentation, vascularity, pliability and height of the scar in its scoring system ${ }^{18}$. The best total score is 0 (range $0-14$ ). The scores were determined at 1 , 3,6 , and 12 months.

Degree of Epithelialization Scale (0-3) was developed in our centre, and evaluations were made every second day for 2 weeks post operatively. The optimal total score is 0 (visual evidence of complete epithelialization of fenestrations) and the worst score is 3 (no evidence of epithelialization).

The scale to evaluate rate of healing was also developed at our centre, and is as follows: Percentage of burned area (affected area/total body surface) was estimated upon arrival using Dubois evaluation of total body surface of the patient. The area covered by the graft was considered $100 \%$, and other areas, where the application of a graft was not necessary, were not included in this evaluation. Each area was assigned a value between 0 and 6 to indicate the percentage of healing, where $0=100 \%$ healed, $1>99 \%, 2>95 \%, 3>90 \%, 4>80 \%, 5>60 \%$, and $6<60 \%$. The evaluations were made every second day for 2 weeks post operatively.

\section{Pain evaluation}

Visual Analog Pain Scale (VAPS; best total score=0), which has been standardized for clinical application previously $^{19}$, was used for evaluation one day prior to grafting and every second day for 2 weeks post operatively.

\section{Graft Pruritus}

Visual analog pruritus scale (VAPrS) has been standardized previously ${ }^{20}$. Scoring ranges from between $0-10$, with 0 indicating total lack of pruritus and and 10 most severe pruritus. Evaluations were made one day prior to grafting and then every second day for 2 weeks post operatively.

\section{Data analysis}

Initial statistical analysis was conducted using IBM SPSS, version 18 for Windows (ACREA CR, Inc.). All reported $P$-values are two-sided, and only $P$-values less than 0.05 were considered statistically significant. Continuous variables are reported as mean \pm standard error of means (SEM), categorical variables as frequency and percentage. Standard distribution of the data could not be assumed due to small sample size, and the changes of hematological and biochemical parameters over time (prior to surgery, day 7, 14, 90 post surgery) were analyzed using non-parametric, related samples Friedman's two way analysis of variance by ranks with all pair wise multiple comparisons. Mathematical statistics was not the best tool for analysis of the data because (1) the sample size was only 18; (2) there was a high inherent inter-individual and intra-individual variability; (3) the data probability distributions were non parametric; (4) they were highly heterogeneous, and (5) the "outliers" contained very valuable information, that would have been missed if standard statistical tests were applied. We therefore used non-statistical methods based on mathematical gnostics. The method incorporates: i) robust probability distribution of different parameters at multiple time points (both static and dynamic analysis), ii) robust correlation between parameters, iii) robust multi-dimensional analysis, and iv) robust testing of hypotheses ${ }^{21}$. The methods were adopted from methodological sources, published applications, and the tools based on computation system of R-project ${ }^{\mathrm{TM}}$.

\section{RESULTS}

The demographics, extent and etiology of deep burn trauma of the 18 patients seen at the University Hospital Ostrava between January 2009 and December 2010 are summarized in (Table 1). The hospital stay statistics are summarized in (Table 2). Despite the length of surgery having been significantly elevated $(P<0.02)$, the length of hospital stay was significantly decreased $(P<0.06)$, and there was a trend to a shorter hospital stay in the DESG/ APC group. Seventeen out of the 18 patients were treated by primary intent and 1 following a secondary disintegration of a partially healed wound on the face. 
Table 1. Patients demographics.

\begin{tabular}{lc}
\hline Demographic & Mean +/SEM \\
\hline Age & $54.94+/-4.1$ \\
Gender & M:F 9:9 \\
Smokers & $7 / 18(38.9 \%)$ \\
Diabetes & $1 / 18(5.55 \%)$ \\
Hyperlipidemia & $2 / 18(11.1 \%)$ \\
Cardiovascular Disease & $7 / 18(38.9 \%)$ \\
Hematological malignancy & 0 \\
Thrombocytopenia & 0 \\
Chronic renal failure & 0 \\
Systolic BP & $138 \pm 3.0$ \\
Diastolic BP & $78.8 \pm 1.4$ \\
Body temperature & $36.8 \pm 0.1$ \\
Height [cm] & $168.4 \pm 2.2$ \\
Weight [kg] & $75.9 \pm 3.3$ \\
BMI & $26.4 \pm 1.0$ \\
Average burns extent of TBSA [\%] & $9 \%(1 \%-18 \%)$ \\
Average grafted area of TBSA [\%] & $3 \%(1 \%-10 \%)$ \\
Liquid source of burns & $8 \mathrm{pts}$ \\
Flame source of burns & $7 \mathrm{pts}$ \\
Metallurgic slug & $\mathrm{pt}$ \\
Gas explosion as source of burn & $0.0 \mathrm{pt}$ \\
\hline
\end{tabular}

Avarage burns extent of TBSA [\%] and grafted area of TBSA [\%] with the etiology of deep burn trauma.

\section{Patient evaluation}

Visual Analog pain scale (VAPS) results are summarized in (Fig. 1A). Approximately $78 \%$ of patients required analgesics prior to the surgery (Fig. 1B), but by $14^{\text {th }}$ postoperative day (the end of the monitoring period) only $6 \%$ of patients still required analgesics. The role of inflammation in loss of graft, edema and inflammation is shown in (Fig. 1C,D). Each individual curve represents the relationship between pain and leukocytes at a given time by means of the conditional probability function denoted Probability $\{\mathrm{x} \mid \mathrm{y}\}$. The different colors define time and condition: prior to the procedure patients had pain scores of either $>2$ (out of 10) (black) or $<2$ (red); at 7 days patients either had no pain (magenta) or pain $>1$ (blue); by the 14 th day only $6 \%$ of patients had low pain (brown), with scores $>1$, while the rest were pain free (green).

Visual Analog Pruritus Scale (VAPrS) The use of the combination DESG/APC appeared to markedly reduce the level of pruritus (Fig. 2A), an established predictor of hypertrophic scars ${ }^{20}$, compared to historical data (shaded area) and corresponded with greatly reduced antihistamine use (Fig. 2B). The frequency of patients using antihistamines reached a minimum (17/18 or $94 \%$ ) at post-operative day 4 and remained at low levels (78\% medication free) throughout the observation period (up to 12 months). The few patients remaining on anti-histamines beyond this time did not appear to benefit from the medication. Decrease in pruritus correlated to absence of scarring, and the decrease matches the fact that the majority of patients did not to need antihistamines throughout the observation period (12 months) (Fig. 2C). Most notably, the patients with pruritus had low levels of eosinophils throughout the study, suggesting that the mechanism of pruritus may not be histamine related (Fig. 2D).

\section{Graft healing}

The healing of the graft was associated with less complications from infections, decreased graft failure and better acceptance by patients than traditionally observed. The degree of wound healing was evaluated and assigned a score, as described in Materials and Methods. By the fourth day, a third of the wounds were $>99 \%$ healed (Fig. 3). By the end of the study period (18 days) 94\% of the wounds were $99 \%$ or greater healed.

Table 2. Cost analysis of in hospital stay.

\begin{tabular}{|c|c|c|c|c|c|}
\hline & $\begin{array}{c}\text { DESG/APC } \\
\text { (Mean) }\end{array}$ & SEM & $\begin{array}{l}\text { DESG } \\
\text { (Mean) }\end{array}$ & SEM & T-test \\
\hline $\begin{array}{l}\text { Surgery time } \\
\text { (Min) }\end{array}$ & 121.5 & 5.45 & 81.25 & 7.63 & 0.002 \\
\hline $\begin{array}{l}\text { Hospital stay } \\
\text { (Days) }\end{array}$ & 18.5 & 1.28 & 27.2 & 1.93 & 0.006 \\
\hline $\begin{array}{l}\text { Cost } \\
\text { (Thousands-CZK) }\end{array}$ & 48.2 & 1.03 & 64.6 & 1.39 & 0.169 \\
\hline
\end{tabular}


The highest total Vancouver Scar Scale Score was 4 (median) and occurred at 3 months post surgery. After this point, the median VSS score decreased steadily, reaching 2 (the lowest point) at 6 months and remaining at this score for 1 year. This score of 2 was due to hyperpigmentation in the 6 patients. Most importantly, all of the scars were without any marks of hypertrophy or contractures; thus, avoiding the need for secondary intervention or contraction release (Fig. 4).

While epithelialisation occurred no faster than traditionally observed, the quality of the epithelialisation, as judged by absence of inflammation and good fixation of
Table 3. Platelet Rich Plasma Analysis.

\begin{tabular}{lrr}
\hline Platelet Rich Plasma & Mean & SEM \\
\hline Platelet count (x10 $/$ L) & 1011.94 & 69.58 \\
Platelet volume (fL) & 9.70 & 0.29 \\
Platelet distribution width (\%) & 10.98 & 0.58 \\
Immature Platelet Fraction (\%) & 2.75 & 0.66 \\
\hline
\end{tabular}

Platelet rich plasma sample analysis of the $60 \mathrm{~mL}$ of peripheral blood after $15 \mathrm{~min}$ of gradient density centrifuge procedure with Harvest SmartPRep Platelet Concentrate System.

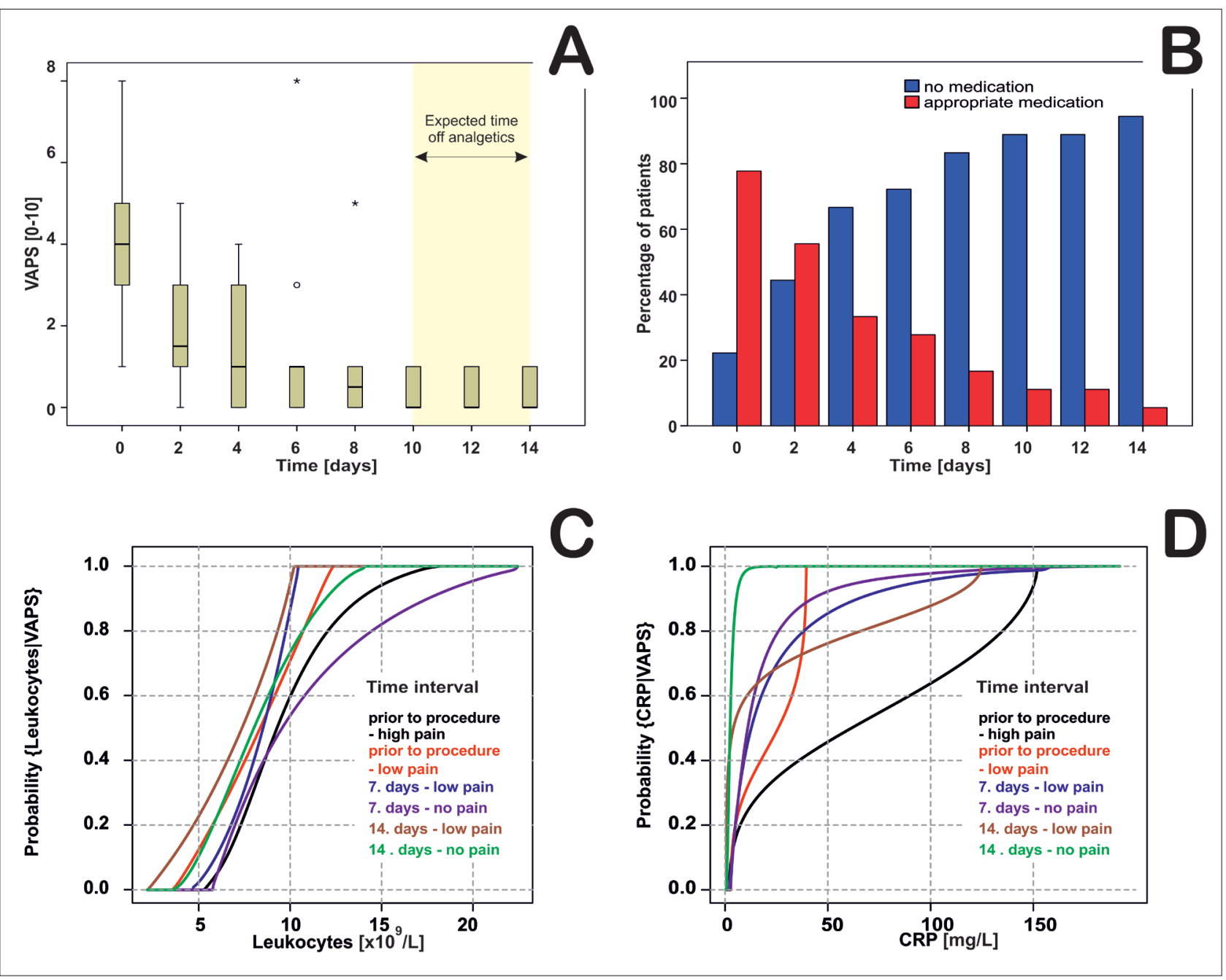

Fig. 1. Post operative pain assessment after DESG.

A) Visual Analog Pain Scale (VAPS): Patients treated with APC and DESG were evaluated using a VAPS from 0-10. As evident, most were pain free by day 6. The shaded area in A indicates historical experience with pain disappearance.

B) Percentage of Patients on analgesics. Prior to surgery, approximately $78 \%$ of patients required analgesics, by the $2^{\text {nd }}$ post-operative day, the number dropped to $56 \%$, by the $4^{\text {th }}$ post operative to $33 \%$ remaining on analgesics, and by $14^{\text {th }}$ post-operative day (the end of the monitoring period) only $6 \%$ of patients require analgesics.

C) Impact of Leukocytes on the Pain Evaluated in Visual Analog Pain Scale. The curves are gnostic distribution functions of leukocytes conditioned by a certain level of pain. Each individual curve represents the relationship between VAPS and leukocytes at a given time. Prior to DESG the VASPS some patients had 2/10 pain (black curve), or less than 2/10 pain(red curve), at 7 days, there are patients without pain (purple) and with pain over 1 (blue), by the $14^{\text {th }}$ day only $6 \%$ of patients have pain (brown) over 1 and the rest is pain free (green).

D) Interpretation of VAPS using Distribution Functions. The curves represent the conditional probability (in this case probability of c-reactive protein influencing pain). The diversion of the probability curves indicates that $82 \%$ of the patients with high CRP also had high pain prior to procedure. At 7 days those with pain and those without pain had nearly the same concentration of CRP, and finally at 14 days those in whom inflammation persisted had high pain (brown) and those with low CRP had no pain (green). 


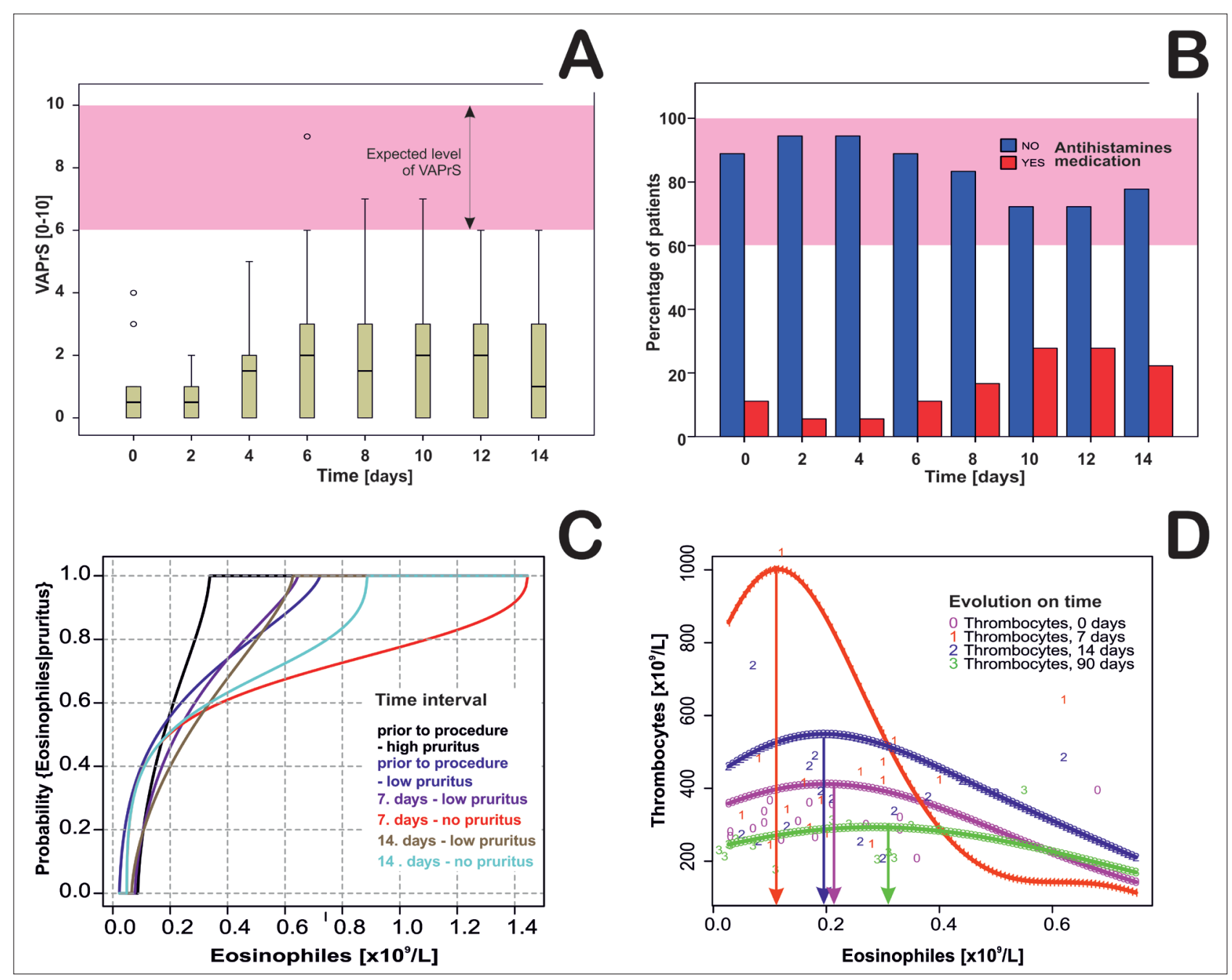

Fig. 2. Post operative pruritus assessment after DESG.

A) Visual Analog Pruritus Scale (VAPrS): The range of the scale is from 0-10. As evident, degree of pruritus was lower than in patients not treated with DESG/APC (shaded area). Pruritus drops from pre-procedural levels, reaching a nadir at 7 days, and then raising again with healing (B). B) Percentage of Patients using antihistamines. Percentage of patients on antihistamines was used as a surrogate for pruritus and scar formation. On the $2^{\text {nd }}$ and $4^{\text {th }}$ post-operative day $17 / 18$ patients $(94 \%)$, and on $14^{\text {th }}$ postoperative $14 / 18(78 \%)$ patients did not require any antihistamines. C) Interpretation of VAPrS and eosinophils using Distribution Functions. Each individual curve represents the relationship between eosinophils and pruritus at a given time. Prior to surgery there was $\sim 55 \%$ of patients who had low levels of eosinophils and high pruritus (note the value at which blue and black curves cross) and the remainder had low eosinophils and high pruritus (blue curve). At 7 days the low pruritus line (purple) and no pruritus lines (red) intersect at about $50 \%$. Decrease of pruritus was correlated to absence of scarring, and the decrease of pruritus is in agreement with the finding that majority of patients continued not to need antihistamines throughout the observation period (12 months).

D) Relationship between platelets and eosinophiles analyzed using Distribution Functions. Their inter-relationships reveal that at 7 days there are low eosinophiles and high platelets (significant at $0 \cdot 1$ eosinophiles, red line). At 14 days, platelets decrease, but remain higher with a peak of $600 \times 10^{9} / \mathrm{L}$, and by 3 months both eosinophiles and platelets are in normal ranges. Most notably, the patients with pruritus had low levels of eosionophils throughout the study, suggesting that the mechanism of pruritus may not be histamine related. This would agree with the finding that those patients using anti-histamines to control pruritus do not get relief from the medication. 
Table 4. Coagulation statistical analysis.

\begin{tabular}{lcccccc}
\hline & Day & Day & Day & Day & Day & Day \\
& $0-7$ & $0-14$ & $0-90$ & $7-14$ & $7-90$ & $14-90$ \\
\hline APTT & & $\downarrow P=0.003$ & & $\downarrow P=0.026$ & $\downarrow P=0.003$ \\
TT & & & & & \\
Fbg & & $\downarrow P=0.006$ & $\downarrow P=0.000$ & $\downarrow P=0.016$ & $\downarrow P=0.000$ & $\downarrow P=0.000$ \\
Platelets & $\uparrow P=0.026$ & & & & $\downarrow P=0.000$ & \\
INR & & $\uparrow P=0.032$ & $\uparrow P=0.041$ & & & \\
\hline
\end{tabular}

个 Significant increase $\downarrow$ Significant decrease

Activation of the coagulation cascade. A clot is necessary for the creation of a platelet rich fibrin/collagen matrix that facilitates early phases of wound healing by providing a scaffold for the migration and homing of inflammatory and mesenchymal cells. While aPTT, TT, INR and platelets are higher than normal at 7 days suggesting a compensated disseminated intravascular coagulation in the first week post procedure, all parameters gradually improve over the 14 days and normalized by 90 days by significant decrease.

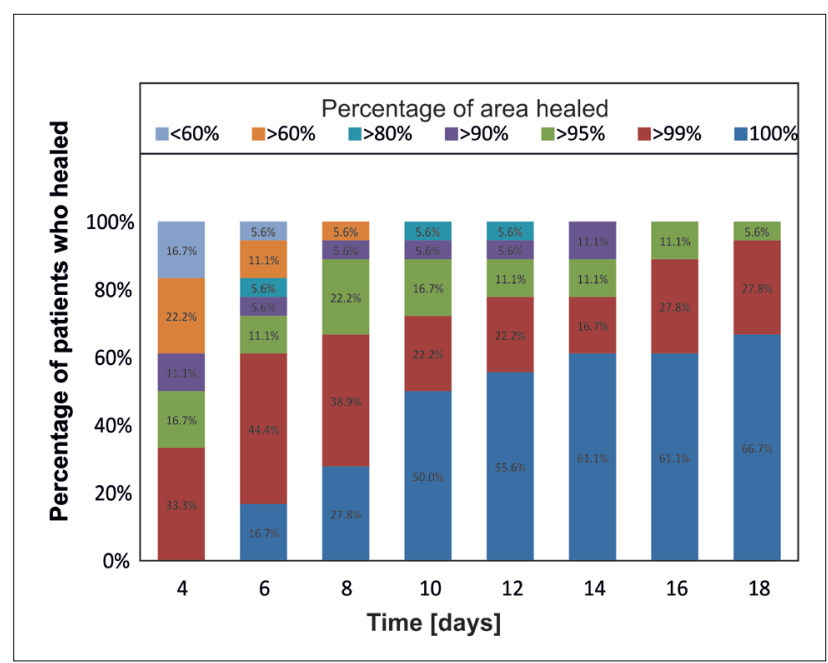

Fig. 3. Rate of Healing. The rate of wound healing was evaluated on a scale $0-100 \%$. The majority of graft area (more than $99 \%$ ) was healed in $33 \%$ of patients on the $4^{\text {th }}$ post-operative day, in $61 \%$ on the $6^{\text {th }}$ day, in $67 \%$ on the $8^{\text {th }}$ postoperative day, in $72 \%$ on the $10^{\text {th }}$ day, $78 \%$ on the $12^{\text {th }}$ day and $94 \%$ of patients on the $18^{\text {th }}$ post-operative day. The healing seen with DESG and platelets occurs earlier is more robust.

the tissue to the wound bed, was greatly improved. Most grafts $(72 \%$ of patients) were completely reepithelialised by the tenth day (Fig. 5A). Improved epithelialisation was also associated with statistically significant suppression of the inflammatory response as measured by decrease in CRP and fibrinogen levels in the plasma of those patients with faster healing wounds (Fig. 5B,5D). There was no apparent correlation with reepithelialisation rate and leukocyte counts (Fig. 5C).

\section{Coagulation and Haematological analysis}

The evolution of coagulation parameters over time following treatment with DESG/APC was evaluated (Fig. 6). The tendency for early healing (rate of graft healing $<2$ on day 4), or late healing (rate of graft healing $<2$ on day

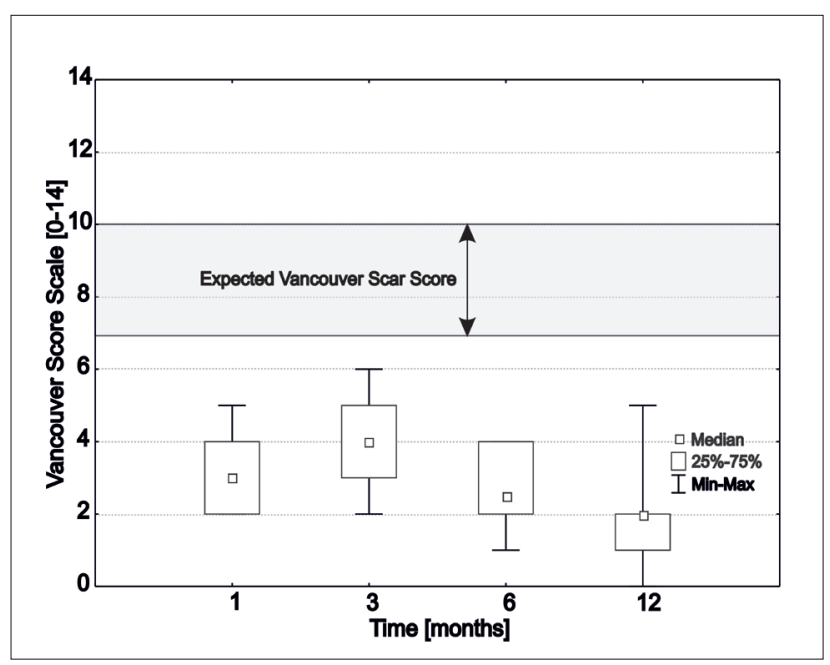

Fig. 4. Vancouver Scar Score Scale. The scale score is based on: pigmentation (0-3), vascularity (0-3), pliability (0-5), and scar height (0-3) with a maximum achievable score of 14 . The Vancouver Scar Score ratings of patients not treated with DESG and platelets range between 7-10 (grey shaded area), mainly because $40-60 \%$ of these patients have scar hypertrophy (1). In our study, patients treated with the combination show a remarkable decrease of scores with maximum scores achieved at 3 month (median=4) and high quality scar (median=2) from 12 months onward.

6), was not related to platelet counts, MPV, or Immature Platelet Fraction (data not shown). The methods of analysis for Coagulation parameters (aPTT, INR, Fibrinogen, Platelets and Thrombin Time) were suggestive of compensated disseminated intravascular coagulation (Fig. 6) and are summarized in (Table 4). The levels of cellular indicators of inflammation and stress corresponded to the observed clinical decrease of inflammation (Fig. 7). The normalization of lymphocyte counts reached significance by the $7^{\text {th }}$ postoperative day $(P=0.21)$, and remained so throughout the early post-operative and late stages $(P=0.27)$ on day 90 (Fig. 7C). A significant decrease in monocyte counts was also observed throughout the follow up period (day 0-14, $P=0.05$; day $0-90, P=0.03$ ) (Fig. $7 \mathrm{E}$ ), indicating early resolution of inflammatory response, 


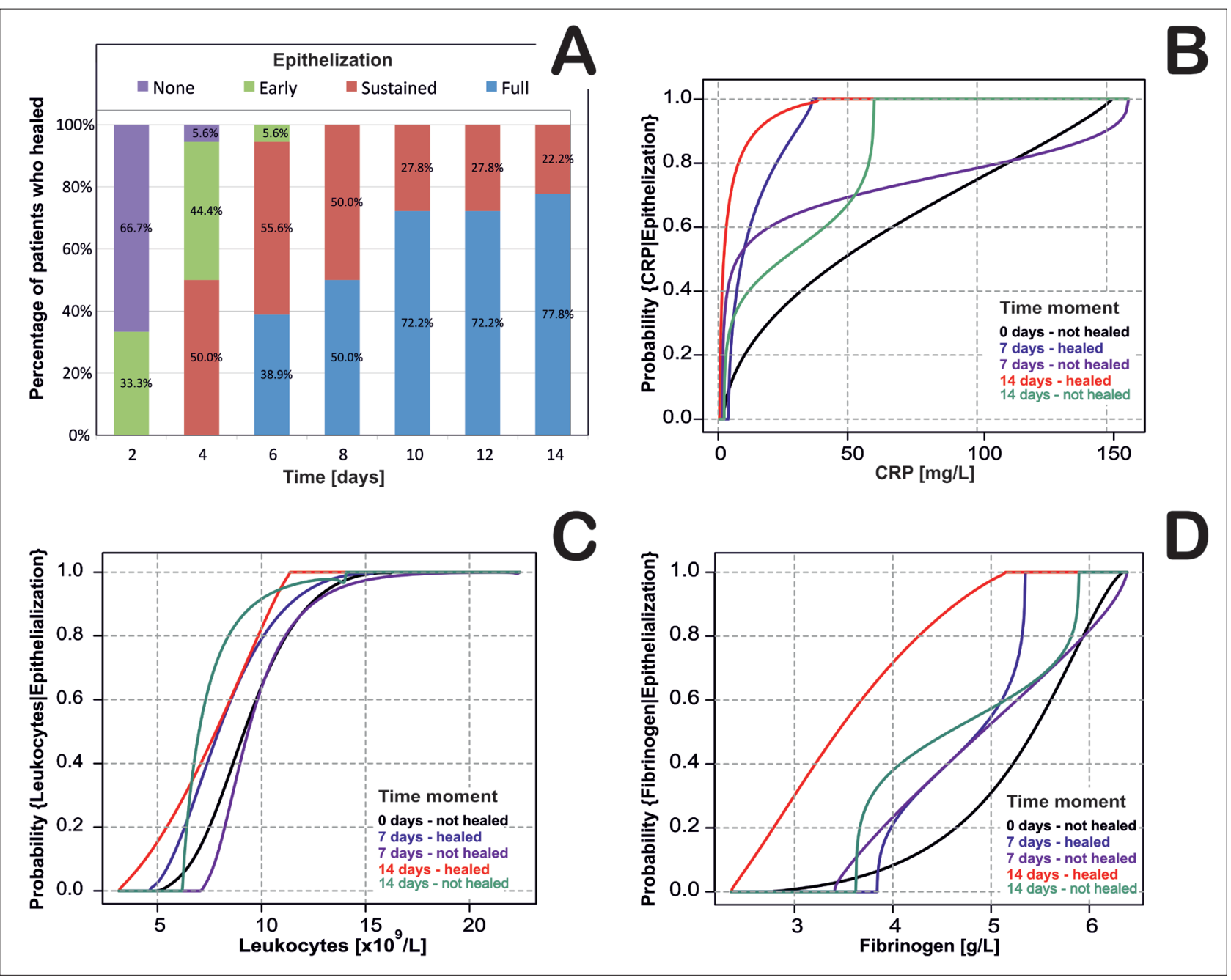

Fig. 5. Inflammation during re-epithelialization.

A) Rate of post-operative re-epithelialization. The rate of epithelization was evaluated using a scale from none $=3$ points, early $=2$, sustained $=1$, and full $=0$. We found that most grafts ( $72 \%$ of patients) were completely epithelialized by $10^{\text {th }}$ day.

B) Conditional distribution functions correlating epithelialization and c-reactive protein (CRP) at 0, 7 and 14 days. It appears that better epithelialization on the $7^{\text {th }}$ and $14^{\text {th }}$ post operative day are related to a lower CRP (red and blue line).

C) Distribution functions correlating epithelization and leukocyte levels. At 7 days all patients without healing have higher leukocyte counts (purple line) than those that healed (blue line. In contrast at 14 days the patients who have not healed have lower levels of leukocytes, while higher levels of leukocytes are correlated to better healing (red line). However, because the majority of patients (78\%) were healed at 14 days, leaving few patients for calculation of this curve, it is difficult to reach the later conclusion.

D) Dependence of epithelialization on the fibrinogen levels. Following healing (at 14 days) fibrinogen levels appear to have dropped (red line) to less than baseline (black line at day 0 ). At 7 days there appear to be only small differences between healers and non-healers.

which corresponded well with perfusion data (Fig. 10) as well as the clinical evaluation of wounds (Fig. 12). Because the initial values were obtained during acute injury, the comparison was made with the values at 3 months when all patients had healed and exhibited no evidence of inflammation (Fig. 7). A reactive increase in red blood cells hemoglobin and hematocrit was seen on days 7-90 (Fig. 7B,F), most likely reflecting no blood loss.

\section{Cytokines analysis}

The blood elements carry a cargo of growth factors, inflammatory cytokines and chemoattractants for mesenchymal cells, and we analyzed the relationships between the different cytokines in the initial platelet concentrate used for the grafting. The levels of growth factors in platelets correlated not only with platelet and neutrophil counts and mean platelets volume, but also with the rate of graft healing. A strong inverse correlation was found between the MPV levels and SDF-1 counts. Similarly strong positive correlations were observed between platelets, neutrophils and the amount of growth factors, confirming that VEGF is accumulated in platelets and neutrophils (Fig. 8).

\section{Histolopathology}

Patients with DESG containing all layers (dermal, epidermal, fibrin/collagen adventitia) (A) appeared to be healing faster and their grafts retained better integrity 


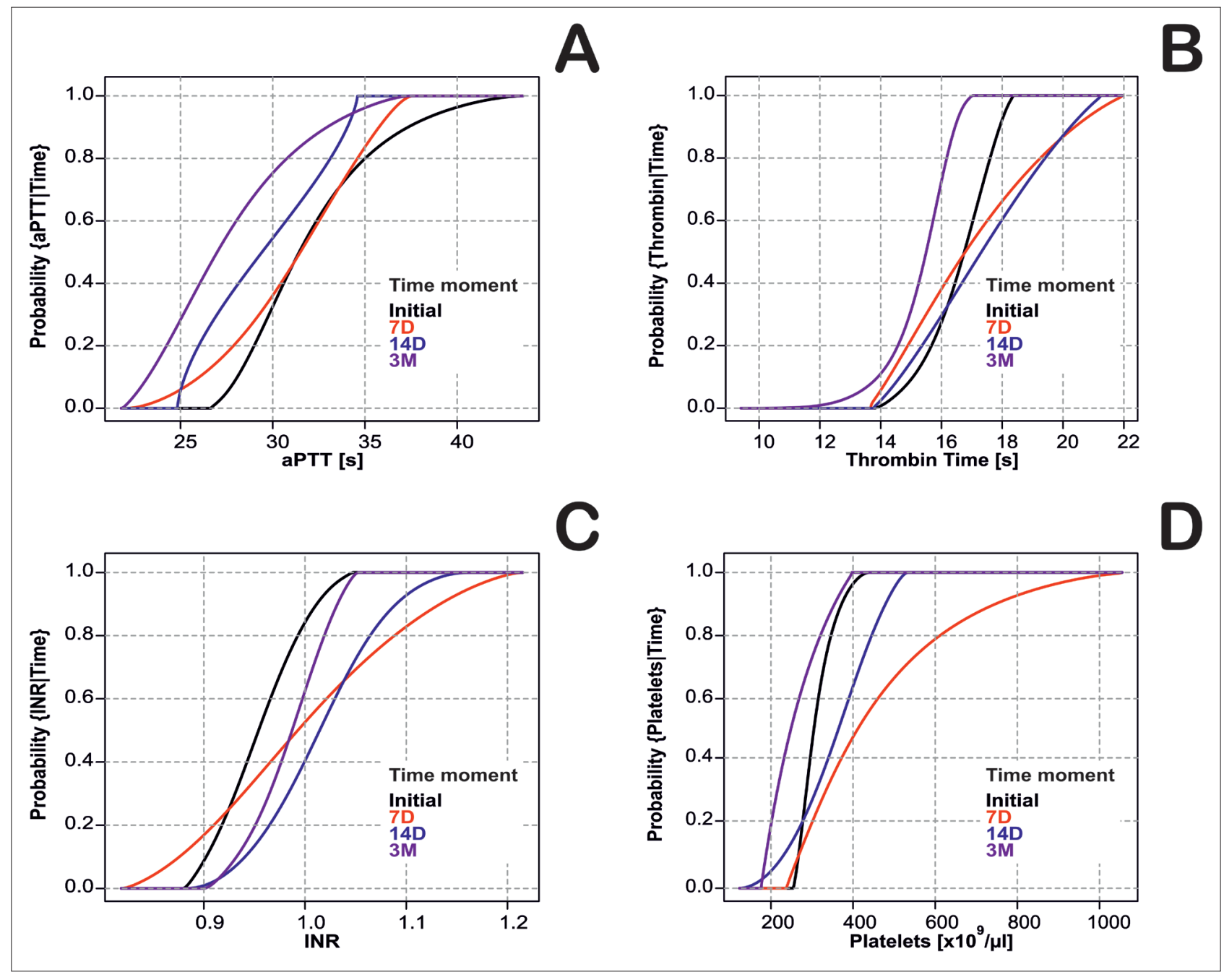

Fig. 6. Distribution of individual coagulation parameters.

A) Evolution of Distribution Functions of aPTT: While values of aPTT are higher than normal at 7 days (black curve vs red curve), they gradually normalize at 14 (blue) and 90 (purple) days.

B) Evolution of Distribution Functions of TT. The values of TT are higher than normal at 7 days in about half of cases (black vs red curve), they remain elevated at 14 days (blue), and gradually normalize by 90 days (purple). The value of TT following the surgery (cross of the black line with blue and red) remains high and very variable in over $50 \%$ patients at 7 and 14 days, but normalizes at 3 months.

C) Evolution of Distribution Functions of INR. The value of INR is elevated and very variable in nearly $80 \%$ patients at 7 days. At 14 and 90 days the values somewhat normalize, but never reach initial levels.

D) Evolution of Distribution Functions of Platelets. Platelet levels at 7 days following surgery are significantly elevated and very variable in over $90 \%$ patients (cross of the black line with red), and they gradually normalize and correct to values less than those at initial (black curve) by three months.

throughout. Thin grafts (B) usually missed sub-epidermal layers, and resulted in delayed healing, mainly due to lack of firmness and increased secretions, leading to less stable grafts at 3 months. Viable platelets and PDGF could be demonstrated in all patients who received DESG/APC. The cellularity of the germinal layer of the graft correlated with graft viability; conversely, lack of cellularity and increased number of apoptotic nuclei within the germinal layer indicated decreased rate of healing (Fig. 9). The expression of PDGF (Fig. 9E,F), and bFGF (Fig. 9C,D) was confined to the germinal layer, an area most commonly inhabited by progenitor cells. The presence of viable progenitor cells was corroborated by histochemical evidence of CD34/PDGF and CD34/ SDF-1 co-localization in the germinal layers (Fig. 9E,F,G,H).

Laser doppler perfusion, measured in perfusion units (PUs), showed a florid initial perfusion, a gradual decrease in perfusion during the first six days, followed by healing angiogenesis within a one month period (Fig. 10,11). All 18 patients had at least one pre-operative scan indicating pathologic post-traumatic inflammation with an increase in perfusion; following grafting, inflammatory reduction is reflected as a relative decrease in perfusion, before a secondary increase in perfusion after 14 days that indicates engraftment and angiogenesis. Following this 


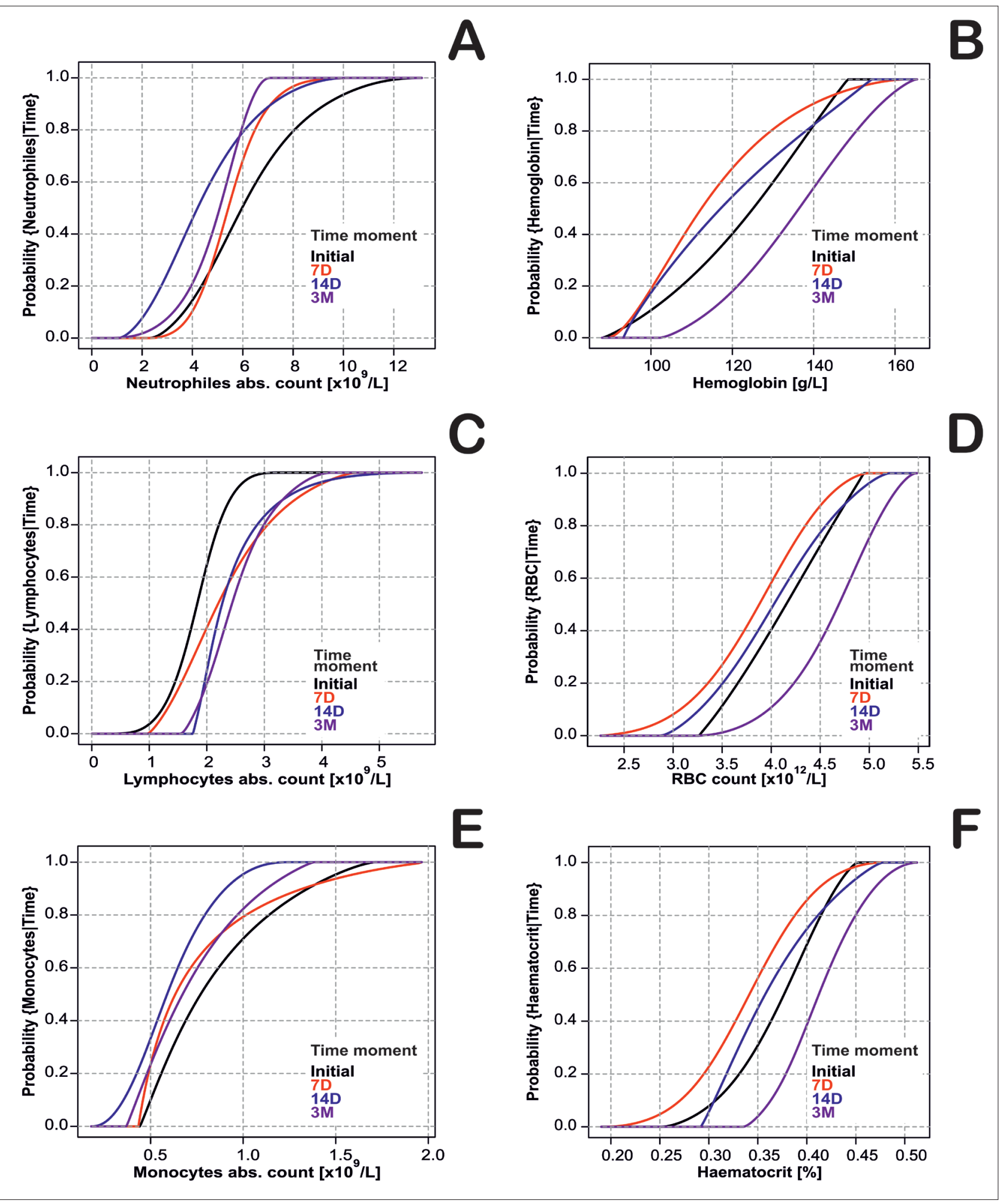

Fig. 7. Evolution of distribution functions of hematological elements. Following DESG/APC grafting. There is evidence of initial blood loss (left shift of the red curve) in hemoglobin, hematocrit and red blood cells analysis, with gradual stabililization of the curves over time on the level substantially exceeding the initial state. Dynamics of changes in neutrophile, monocyte and lymphocyte levels is less considerable but not negligible. 


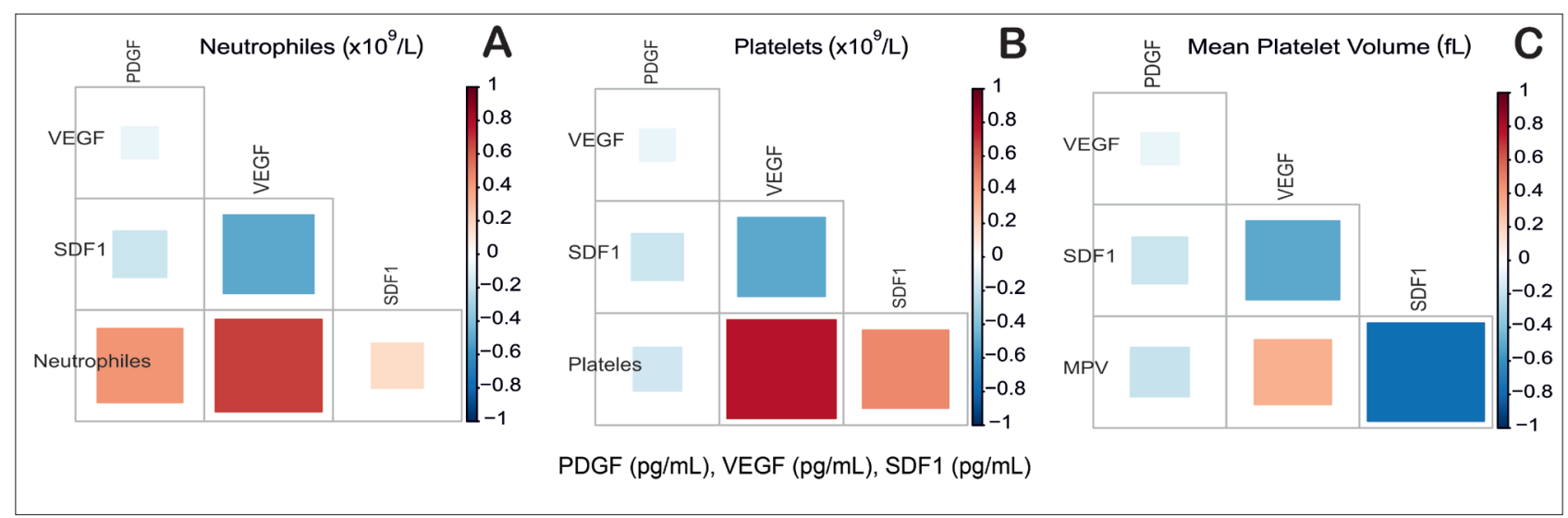

Fig. 8. Correlation diagrams for cytokines interactions. Heat map diagrams of correlation coefficients of individual selected cytokines, where blue represents a negative correlation [-1 to 1] and red represents a positive one [1 to -1]. The color and size of each individual square indicates a quantitative measure of the correlation. The diagram shows the correlations of neutrophiles, platelets or MPV (always in the left lower corner of the diagram), with 3 cytokines (VEGF, SDF1, PDGF). In the case of neutrophiles (A) and platelets (B), the strongest positive correlation is between VEGF and neutrophiles (or VEGF and platelets in B). Mean platelet volume (B) has a very strong negative correlation with SDF1. The correlation of VEGF and PDGF is very weak in all three correlations.

secondary peak and tissue regeneration, there is gradual drop in average perfusion at 360 days, indicating restoration of vascular quiescence.

Clinical evaluation by digital photography was done on day 2, 4, 6, 8, 10 and 14 after surgical procedure (see Fig. 12). Patient 1 was burned by melted metal on the job, and he was grafted on the $6^{\text {th }}$ day post injury, $3^{\text {rd }}$ degree burns covered $1.75 \%$ of TBSA. Complete healing was achieved by 8 days (A3), and a month later a normally pigmented, non-hypertrophic scar devoid of any contractures was noted. Patient 2 burned herself with a garden fire, and received the DESG/APC on 14th day post injury. She had $3^{\text {rd }}$ degree burns of $2.5 \%$ of TBSA on the right thigh, popliteal region and calf of right leg (B1). The wound was completely healed by 8 days, and one moth post-surgery (B4) a well-healed scar devoid of contractures, ulcerations or infections is evident. Patient 3 had burned herself while cooking on the hypothenar area of the palm and dorsum of $5^{\text {th }}$ and $4^{\text {th }}$ finger. She had $3^{\text {rd }}$ degree burns on $1 \%$ of TBSA, but involving highly sensitive area of the left hand and fingers. Complete healing was achieved on the $10^{\text {th }}$ post-operative day. At one month the patient had a fully functional hand, and contraction-less scar.

\section{DISCUSSION}

The application of concentrated platelets in the setting of chronic ulcer ${ }^{22,23}$, cardiovascular surgery ${ }^{24}$, orthopedic surgery ${ }^{25,26}$, sternum repair after cardiac surgery ${ }^{27}$ and spinal injury ${ }^{28}$ is increasing. However, in the case of burns, it has not been established whether there is any benefit of platelet therapy. The use of acellular pig dermis matrix consisting of a mesh of collagen and elastic fibres, may result in skin hypertrophy, and cultured keratinocytes lead to thin and unstable grafts ${ }^{29}$. Ideally, new therapies would incorporate progenitor cells capable of differentiating into various dermal cells to increase the quality of healed wounds. Additionally, application of individual agents or scaffolds do not allow for dynamic reciprocity of intercellular interactions that lead to normal tissue regeneration $^{30}$. In this study we attempted to demonstrate benefit through the combination of Dermo-Epidermal Skin Grafts (DESG), which contain progenitor cells within the deep dermal layers, with autologous platelet concentrate (APC), which contains enhanced levels of cytokines and growth factors required to facilitate cellular cross-talk and interactions as well as to enhance recruitment of other cell types resident within bordering host tissues.

The 18 patients treated with DESG/APC were painfree by day 6 (Fig. 1A), and since persistent pain in patients is due to delayed healing, and loss of graft, this supports an improved healing in DESG/APC treated patients. As seen in Figure 1, panel B only $6 \%$ of patients used analgesics at the end of the 14 day monitoring period. The probability of change in leukocyte counts (or CRP levels) under the condition of pain (Fig. 1C,D) indicate an initial (0-7 days) increase in inflammation, followed by a gradual drop in both CRP and leukocytes as pain disappears. This confirms the existing clinical suspicion that CRP and leukocyte counts are excellent markers/ predictors of pain.

Pruritus (itching, edema and redness) could be directly correlated with healing (Fig. 2A,B,C,D). The salient finding from this measurement was that the frequency and severity of pruritus were both 2-3x less than the usually observed 6-10/10 VAPrS (shaded area in Fig. 2A). The somewhat surprising finding was a lack of correlation between eosinophils, platelets and pruritus, supporting the conclusion that pruritus is not in this case related to histamine release, and would not (and did not) respond to anti-histamine therapy. Lessening of pain and pruritus herald healing. In agreement with this are the findings in 


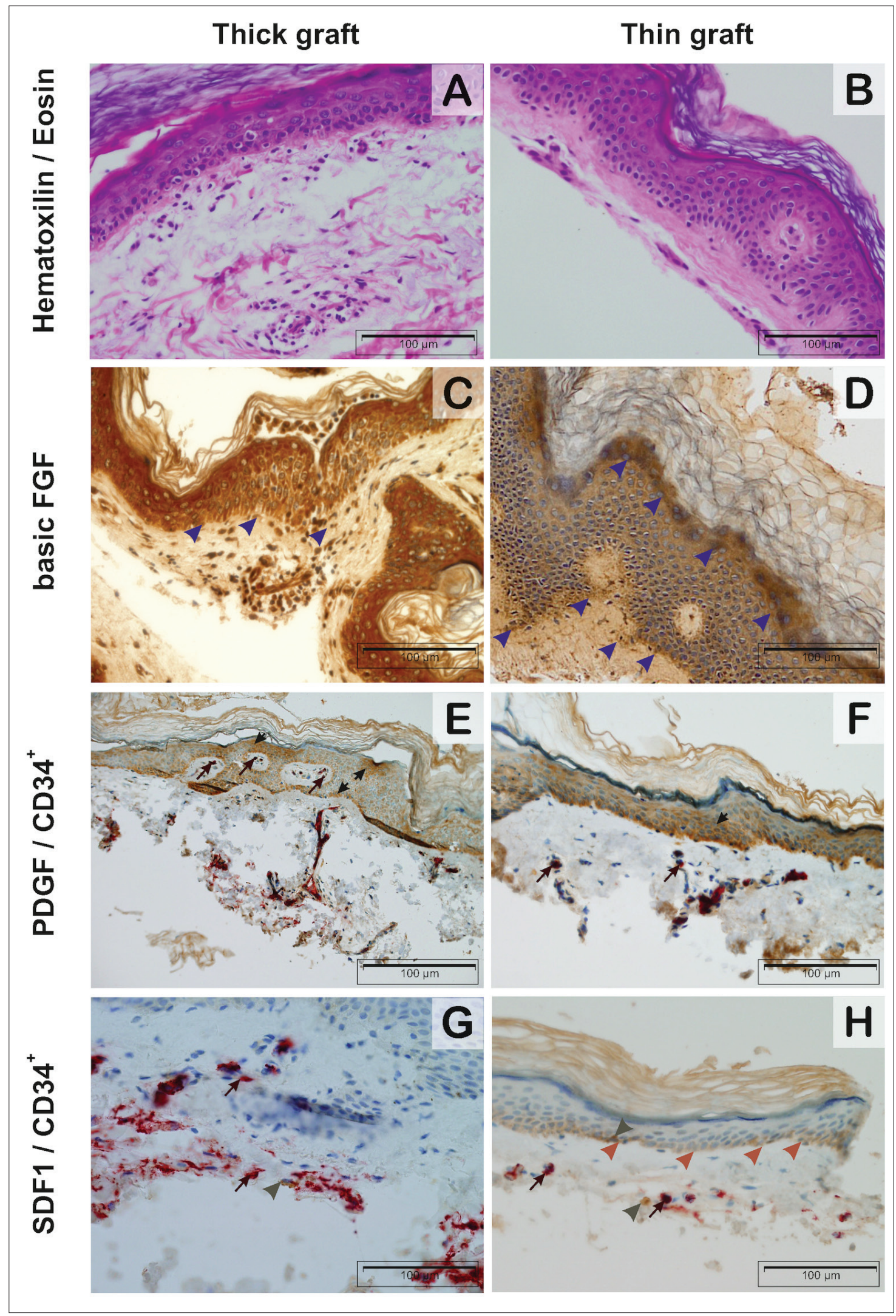

Fig. 9. Histology of DESG/APC at the time of application. Hematoxylin/Eosin: 40x; Immunohistochemistry for bFGF, Platelet Derived Growth Factor (PDGF), SDF1, CD34; was performed on the graft tissues at the time of DESG/APC application. The expression of bFGF localized to the stroma of the germinal layer (blue arrowheads in $\mathrm{C}, \mathrm{D}$ ), and to the junction of keratin layer and epidermis. The expression of PDGF is localized in the stroma of the germinal layer (black arrowheads in E,F), an area commonly inhabited by progenitor cells. Dark red arrows in E,F point to CD34+ cells marked by red stain. The expression of SDF1 is localized to the stroma of the germinal layer (brown arrowheads in $\mathrm{G}, \mathrm{H}$ ), and fibroblastic cells (dark grey arrowheads in $\mathrm{G}, \mathrm{H}$ ). Dark red arrows in $\mathrm{G}, \mathrm{H}$ point to CD34+ cells marked by red stain. 


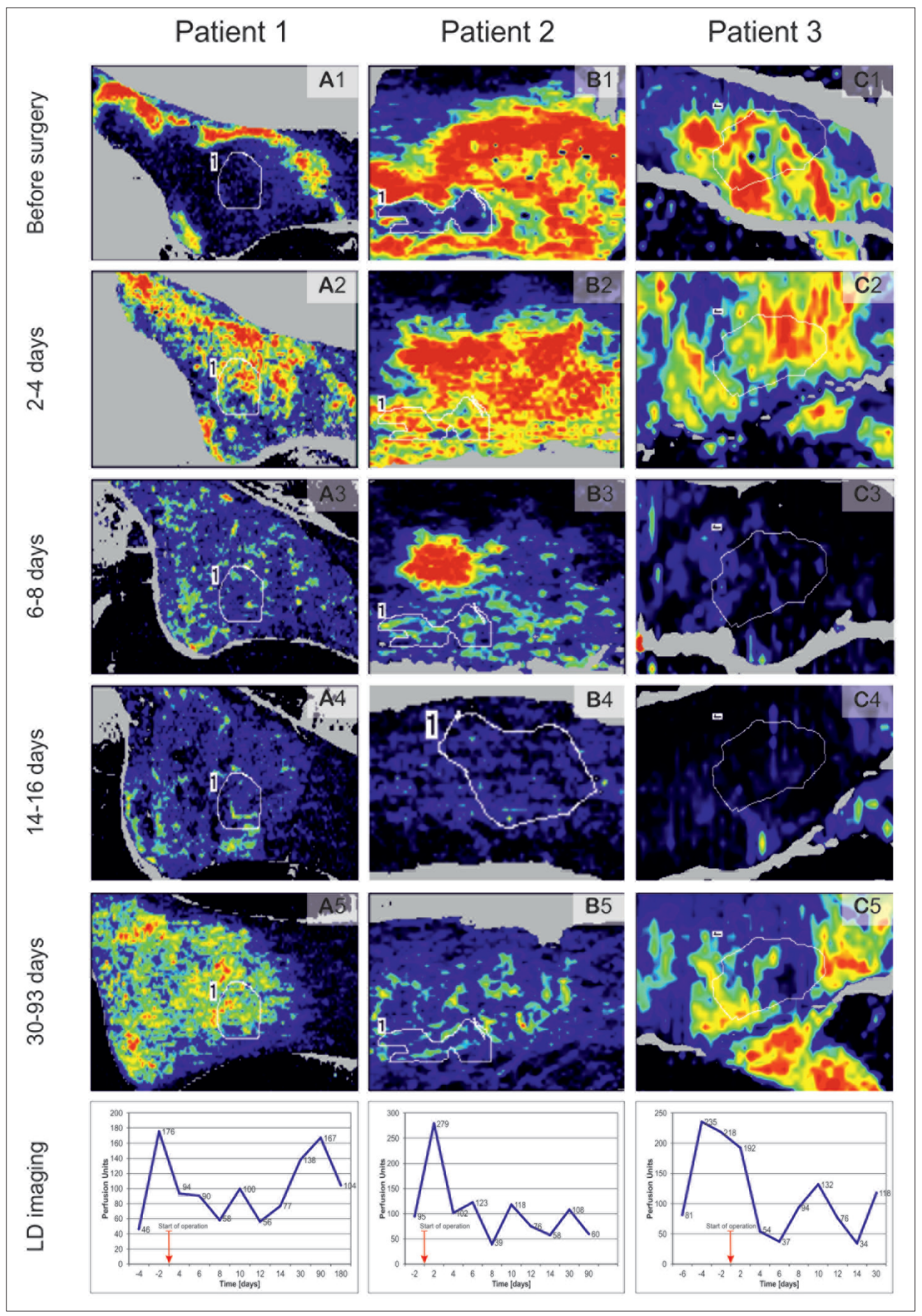

Fig. 10. Laser doppler imaging studies. Were donne on day $0,6,14$ and 30 . Day 0 is prior to any procedure. Each of the images has a defined region of interest (ROI) marked by a white border and labeled " 1 ".

In patient 1 (A1-A5) a pre-operative scan, was done on the $4^{\text {th }}$ post-traumatic day, and showed very low perfusion (46.4 perfusion units, PU), surrounded by inflammatory hallo (A1 on Fig. 10). On the $2^{\text {nd }}$ post-operative day perfusion increased to 176 PU (A2). Next two scans indicate decrease in perfusion to $94 \mathrm{PU}$ on day 4 and to $58 \mathrm{PU}$ on day 8 before a secondary increase in perfusion that occurred with healing, and is evident by a rise to 167 at 93 days. In patient 2 (B1-5) the preoperative scan was acquired 12th post-traumatic day (day -2 of surgery) and showed low perfusion $94.9 \mathrm{PU}$, raising to $279.2 \mathrm{PU}$ in the first 2 days post-op, before gradually decreasing to a nadir of 39.3 on the $8^{\text {th }}$ post-operative day, and stabilized between 57.6-118.1 without a secondary peak. In patient 3(C1-C5) was first scanned 7 days post trauma (day -1), and showed 81.5 PU, raising to $235.4 \mathrm{PU}$, dropping gradually to 37.2 on the $6^{\text {th }}$ post-operative day, and stabilizing between 34.2 and $132 \mathrm{PU}$. 


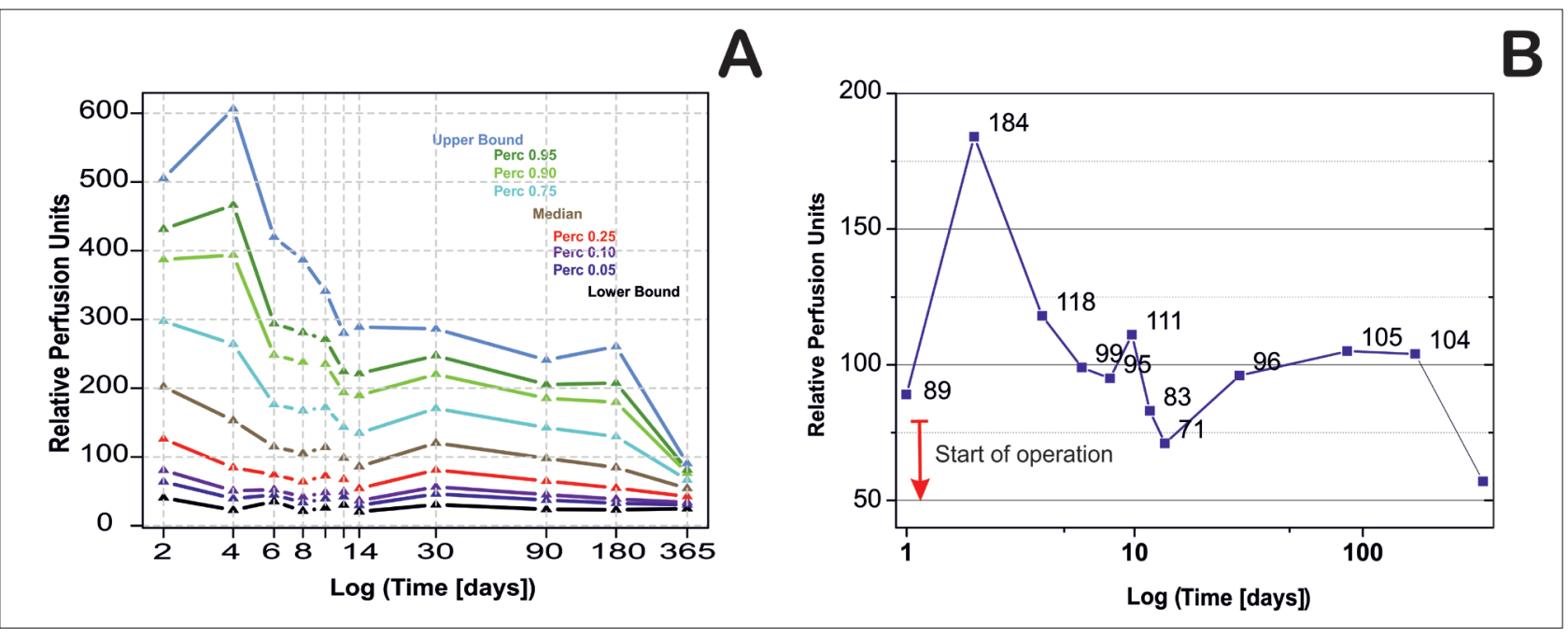

Fig. 11. Laser doppler perfusion study.

A) Dynamic summary of perfusion studies are obtained by estimating the distribution functions of the 11 data sets of RPU (Relative Perfusion Units) for each of the 11 time points. Nine values of percentiles of each of these distributions are calculated for probabilities $0,0 \cdot 05,0 \cdot 1,0 \cdot 25$, $0.5,0.75,0.90$ and 1 . Percentiles are depicted in figure 11 on straight lines parallel to the Y-axis by color marks. It can be seen in Figure 11 that the large starting variability of RPU is still increasing at time $4 \mathrm{D}$ to fall to minimum at $365 \mathrm{D}$.

B) Average perfusion units at each of the 11 time points. All 18 patients had at least one pre-operative scan indicating pathologic post-traumatic inflammation with an increase in perfusion (89); following grafting, inflammatory reduction is reflected as a relative decrease in perfusion that reaches a nadir between 6-14 days (PU 71-111 respectively), before a secondary increase in perfusion after 14 days that indicates engraftment and angiogenesis and peaks between 30-90 days (105 PU). Following this secondary peak and tissue regeneration, there is gradual drop in average perfusion to $61 \mathrm{PU}$ at 360 days, indicating restoration of vascular quiescence.

(Fig. 3) showing a gradual increase in the percentage of healed area, with $>94 \%$ of patients having over $99 \%$ of the burned area healed on $18^{\text {th }}$ post-operative day.

One of the most attractive selling features of the combination of DESG and platelets may be the enhanced cosmesis and characteristics of the scar (Fig. 4 and Fig. 12). In patients not treated with this combination, scar hypertrophy often occurs 1-3 months post-operatively, and peaks at 3 months. The quality of scar formation and patient's ultimate functionality is best predicted by the speed and stability of epithelialization. While the rate of reepithelialization in patients treated with DESG/APC may not have been higher or faster than traditionally observed, the inflammatory markers normalized faster (Fig. 5 B,C,D), making the re-eptithelialized wound more stable. Most grafts ( $72 \%$ of patients) were completely reepithelialized by day 10 (Fig. 5A) creating a natural barrier to infection and preventing usual complications. Because of the minimal cicatrization in patients treated with DESG/APC, they had no need for pressure garments or other scar management.

Activation of the coagulation cascade is seen with any tissue injury (Table 4.). A clot is necessary for the creation of a platelet rich fibrin/collagen matrix that facilitates early phases of wound healing by providing a scaffold for the migration and homing of inflammatory and mesenchymal cells. While aPTT, TT, INR and platelets are higher than normal at 7 days (black and red in Fig. 7 A,B,C,D) suggesting a compensated disseminated intra- vascular coagulation in the first week post procedure, all parameters gradually improved over the 14 days (blue) and normalized by 90 days (magenta).

Activation of coagulation also leads to recruitment of platelets to the site. These blood elements carry a cargo of growth factors, inflammatory cytokines and chemoattractants for mesenchymal cells ${ }^{9,11}$ and we analyzed the relationships between the different cytokines (Fig. 8) in the initial platelet concentrate used for the grafting. Both platelets and neutrophils were shown to be a great source of VEGF see (Fig. 8 A,B), and the VEGF correlated negatively with SDF1, substantiating the very distinct and temporally separated functions of these two cytokines. SDF1 is a chemoattractant for stem cells, whereas VEGF is an initiator of vascular sprouting and is needed only transiently. The histological analysis (Fig. 9) supports this interpretation of cytokine progenitor cell interaction, CD34+ progenitors are in the deep dermal crypts and in perivascular regions (Fig. 9E,F,G,H), whereas the deep epidermis stroma is rich in pro-angiogenic growth factors such as bFGF (Fig. 9 C,D) and PDGF (Fig. 9 E,F). In contrast, SDF1 co-localises with CD34+ progenitor cells (Fig. $9 \mathrm{G}, \mathrm{H}$ ). The final neovascularization is the outcome of a complex network of interactions between transient expression of VEGF (vascular sprout initiation), FGF2 (vascular stalk formation), and PDGF (pericyte recruitment and vessel maturation).

From serial dynamic perfusion studies used to follow up patients grafted with DESG/APC emerged a very characteristic pattern of pathological and physiological angio- 


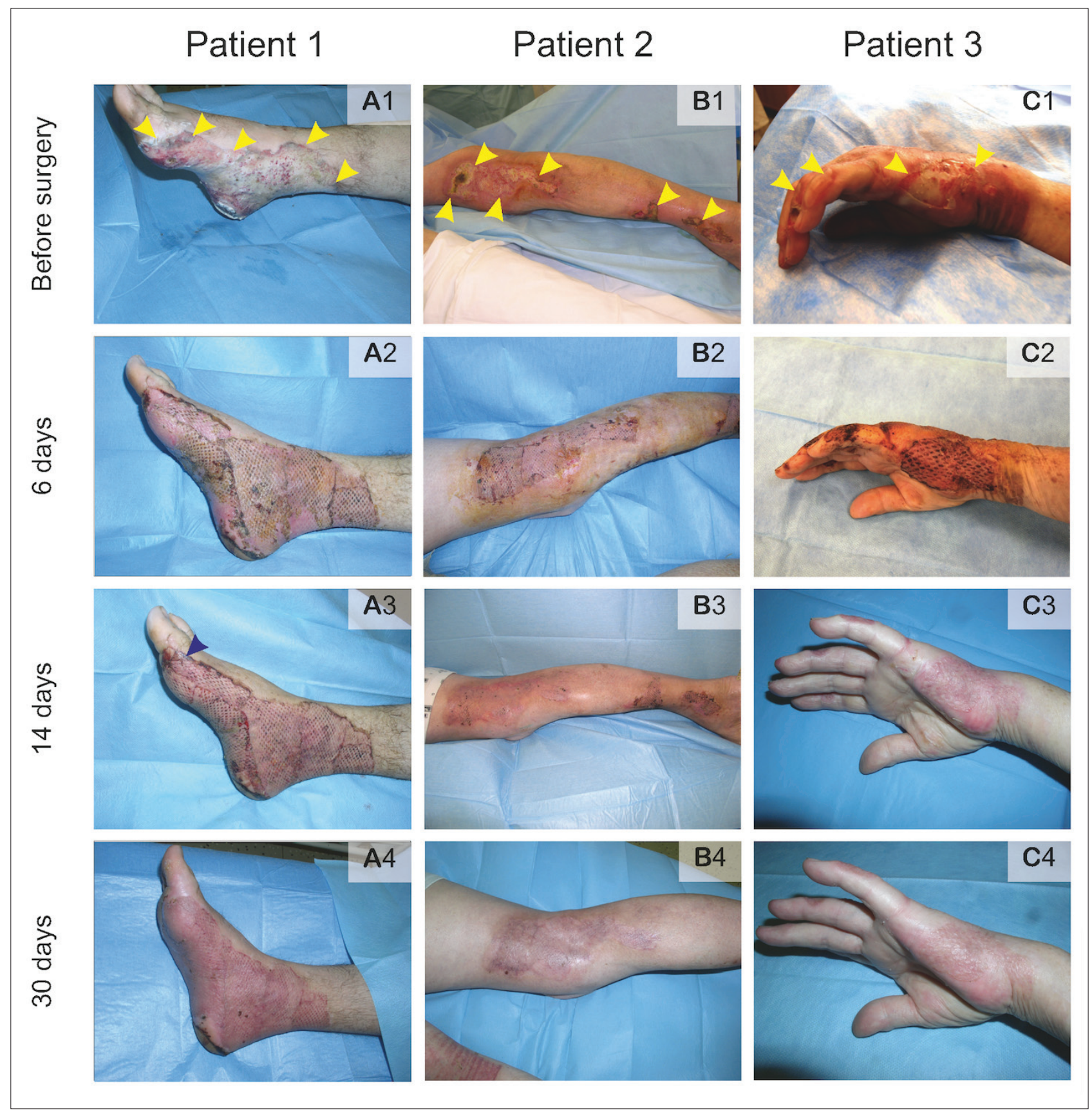

Fig. 12. Clinical evaluation photography. Serial photographs on day 6,14 and 30 post grafting. Each vertical row represents a single patient.

Patient 1 was burned by melted metal on the job, and he was grafted on the $6^{\text {th }}$ day post injury, $3^{\text {rd }}$ degree burns covered $1.75 \%$ of TBSA. On the day of grafting the entire area was necrotic with full thickness damage. On the 6th day (A2) pink granulation tissue well-fixed to the wound bed, and devoid of secretion suggesting a vital skin grafts in over $99 \%$ of the surgically treated area. The blue arrowhead points to the Histoacryl ${ }^{\circledR}$ glue with which the graft is affixed to the tissue. Complete healing was achieved by 8 days (A3), and a month later a normally pigmented, nonhypertrophic scar devoid of any contractures was noted. Heal was the only hyperkeratotic area discolored by iodine. Patient 2 burned herself with a garden fire, and received the DESG/APC on $14_{\text {th }}$ day post injury. She had $3^{\text {rd }}$ degree burns of $2.5 \%$ of TBSA on the right thigh, popliteal region and calf of right leg (B1). On 6th day a vital skin graft was noted in over $99 \%$ of the surgically treated area. The wound was completely healed by 8 days, and one moth post-surgery (B4) a well-healed scar devoid of contractures, ulcerations or infections is evident. Patient 3 had Patient C burned herself while cooking on the hypothenar area of the palm and dorsum of $5^{\text {th }}$ and $4^{\text {th }}$ finger. She had $3^{\text {rd }}$ degree burns on $1 \%$ of TBSA, but involving highly sensitive area of the left hand and fingers. She underwent grafting on the $8^{\text {th }}$ day. On the 6th post-surgical day, fully vital skin grafts were noted on more than $99 \%$ of the surgical area. Complete healing was achieved on the $10^{\text {th }}$ post-operative day. At one month the patient had a fully functional hand, and contraction-less scar. 
genesis (Fig. 11). Following the grafting, the pathologic inflammation regresses and a secondary peak occurs at the time of reperfusion, reflecting healthy regenerative angiogenesis between 1-3 months.

One of the most important findings of this study was the cost effectiveness of the therapy. Despite the longer operating times, the cost of hospital stay was lower (approximately $25 \%$ less) than that of institutional controls who did not receive DESG/APC grafting.

\section{CONCLUSIONS}

Our study indicates that DESG/APC is a combination with superior outcomes to the present standard of care and should be embraced widely. Patients treated with DESG/APC had high quality of healing without evidence of scar hypertrophy or contractures. The intervention markedly benefits patients, the community, and health care in general. We showed that even though the length of time for the initial procedure may have been somewhat longer, significant cost savings in hospital stay and subsequent revisions were achieved.

\section{ABBREVIATIONS}

APC, Autologous platelet concentrate; HAT, Human autologous thrombin; LDPI, Laser doppler perfusion imaging; DESG, Dermo-epidermal skin graft; ACD-A, Acid citrate dextrose-anticoagulant; PDGF, Platelet derived growth factor; VEGF, Vascular endothelial growt factor; bFGF, Beta fibroblast growth factor; SDF1, Stromal cell derived factor 1; VAPS, Visual analog pain scale; VAPrS, Visual analog pruritus scale; TBSA, Total body surface area; MPV, Mean platele volume.

\section{ACKNOWLEDGEMENTS}

United States patent office electronically published application for this method of treatment on June $21^{\text {st }}$, 2012 with the NO: US-2012-0156184-A1. The study was supported by Moravian-Silesian governmental research grant number 02932/2009/RRC. GLK is funded by grants from the NIH NIGMS R01 GM093050-01, by the U.S. DOE DESC0002606, and the NIH NCI ( 1 U54 CA149233-01), and philanthropic funds from Friends for Life and Newman-Lakka Cancer Foundation. The study was approved by IRB - No·16/b2008 on April 30 ${ }^{\text {th }}, 2008$ and registered on ClinTrialsGov as NCT01383187. Many thanks to Pavlina Kusinova coordinating study nurse for APC/HAT preparation in all cases and conducting the case report forms in our clinical study.

Funding was provided by the Council of the Moravian Sileasian region Czech Republic (Grant FNO-99-OVZ09-024-Dot).

\section{CONFLICT OF INTEREST STATEMENT}

The authors state that there are no conflicts of interest regarding the publication of this article.

\section{REFERENCES}

1. Prochazka V, Gumulec J, Jaluvka F, Salounova D, Jonszta T, Czerny D, Krajca J, Urbanec R, Klement P, Martinek J, Klement GL. Cell therapy, a new standard in management of chronic critical limb ischemia and foot ulcer. Cell transplantation 2010;19(11):1413-24.

2. Akingboye AA, Giddins S, Gamston P, Tucker A, Navsaria H, Kyriakides C. Application of autologous derived-platelet rich plasma gel in the treatment of chronic wound ulcer: diabetic foot ulcer. The Journal of extra-corporeal technology 2010;42(1):20-9.

3. Kachel E, Callum J, Moussa F, Goldstein J, Fremes S. Treatment of deep sternal wound infections after coronary artery bypass grafting by means of injection of platelet gel: an evolving technology. The Journal of thoracic and cardiovascular surgery 2010;139(6):e118-20.

4. Martinez-Zapata MJ, Marti-Carvajal A, Sola I, Bolibar I, Angel Exposito J, Rodriguez L, Garcia J. Efficacy and safety of the use of autologous plasma rich in platelets for tissue regeneration: a systematic review. Transfusion 2009;49(1):44-6.

5. Morizaki Y, Zhao C, An KN, Amadio PC. The effects of platelet-rich plasma on bone marrow stromal cell transplants for tendon healing in vitro. The Journal of hand surgery 2010;35(11):1833-41.

6. Langer $H$, May AE, Daub K, Heinzmann $U$, Lang $P$, Schumm $M$, Vestweber D, Massberg S, Schonberger T, Pfisterer I, Hatzopoulos AK, Gawaz M. Adherent platelets recruit and induce differentiation of murine embryonic endothelial progenitor cells to mature endothelial cells in vitro. Circulation research 2006;98(2):e2-10.

7. Stellos K, Seizer P, Bigalke B, Daub K, Geisler T, Gawaz M. Platelet aggregates-induced human CD34+ progenitor cell proliferation and differentiation to macrophages and foam cells is mediated by stromal cell derived factor 1 in vitro. Seminars in thrombosis and hemostasis 2010;36(2):139-45.

8. Pintucci G, Froum S, Pinnell J, Mignatti P, Rafii S, Green D. Trophic effects of platelets on cultured endothelial cells are mediated by platelet-associated fibroblast growth factor-2 (FGF-2) and vascular endothelial growth factor (VEGF). Thrombosis and haemostasis 2002;88(5):834-42.

9. Pietramaggiori G, Scherer SS, Cervi D, Klement G, Orgill DP. Tumors stimulate platelet delivery of angiogenic factors in vivo: an unexpected benefit. The American journal of pathology 2008;173(6):1609-16.

10. Lindemann S, Kramer B, Seizer P, Gawaz M. Platelets, inflammation and atherosclerosis. Journal of thrombosis and haemostasis: JTH 2007;5 Suppl 1:203-11.

11. Klement GL, Yip TT, Cassiola F, Kikuchi L, Cervi D, Podust V, Italiano JE, Wheatley E, Abou-Slaybi A, Bender E, Almog N, Kieran MW, Folkman J. Platelets actively sequester angiogenesis regulators. Blood 2009;113(12):2835-42.

12. Italiano JE, Jr., Richardson JL, Patel-Hett S, Battinelli E, Zaslavsky A, Short S, Ryeom S, Folkman J, Klement GL. Angiogenesis is regulated by a novel mechanism: pro- and antiangiogenic proteins are organized into separate platelet alpha granules and differentially released. Blood 2008;111(3):1227-33.

13. Ma L, Perini R, McKnight W, Dicay M, Klein A, Hollenberg MD, Wallace JL. Proteinase-activated receptors 1 and 4 counter-regulate endostatin and VEGF release from human platelets. Proceedings of the National Academy of Sciences of the United States of America 2005; 102(1):216-20.

14. Bottcher-Haberzeth S, Biedermann T, Reichmann E. Tissue engineering of skin. Burns : journal of the International Society for Burn Injuries 2010;36(4):450-60.

15. Crkvenjas Z, Tymonova J, Adamkova M, Kadlcik M, Klosova H, Zamecnikova I. Surgical treatment of electrical burns by local flap plastic surgery. Acta chirurgiae plasticae 2005;47(1):10-12.

16. Hermann PC, Huber SL, Herrler T, von Hesler C, Andrassy J, Kevy SV, Jacobson MS, Heeschen C. Concentration of bone marrow total nucleated cells by a point-of-care device provides a high 
yield and preserves their functional activity. Cell transplantation 2008;16(10):1059-69.

17. Kloppenberg FW, Beerthuizen GI, ten Duis HJ. Perfusion of burn wounds assessed by laser doppler imaging is related to burn depth and healing time. Burns : journal of the International Society for Burn Injuries 2001;27(4):359-63.

18. Draaijers LJ, Tempelman FR, Botman YA, Kreis RW, Middelkoop E, van Zuijlen PP. Colour evaluation in scars: tristimulus colorimeter, narrow-band simple reflectance meter or subjective evaluation? Burns journal of the International Society for Burn Injuries 2004;30(2):1037.

19. Kabes AM, Graves JK, Norris J. Further validation of the nonverbal pain scale in intensive care patients. Critical care nurse 2009;29(1):5966.

20. Elman S, Hynan LS, Gabriel V, Mayo MJ. The 5-D itch scale: a new measure of pruritus. The British journal of dermatology 2010;162(3):58793.

21. Kovanic PH, Huber MB. The Economics of Information-Mathematical Gnostics for Data Analysis: http://www.math-gnostics.com 2003.

22. Mazzucco L, Balbo V, Cattana E, Borzini P. Platelet-rich plasma and platelet gel preparation using Plateltex. Vox sanguinis 2008;94(3):202-8.

23. Mazzucco L, Medici D, Serra M, Panizza R, Rivara G, Orecchia $S$, Libener R, Cattana E, Levis A, Betta PG, Borzini P. The use of autologous platelet gel to treat difficult-to-heal wounds: a pilot study. Transfusion 2004;44(7):1013-8.

24. Gunaydin S, McCusker K, Sari T, Onur M, Gurpinar A, Sevim H, Atasoy $\mathrm{P}$, Yorgancioglu C, Zorlutuna Y. Clinical impact and biomaterial evaluation of autologous platelet gel in cardiac surgery. Perfusion 2008;23(3):179-86.

25. Coetzee JC, Pomeroy GC, Watts JD, Barrow C. The use of autologous concentrated growth factors to promote syndesmosis fusion in the Agility total ankle replacement. A preliminary study. Foot \& ankle international / American Orthopaedic Foot and Ankle Society [and] Swiss Foot and Ankle Society 2005;26(10):840-6.

26. Gardner MJ, Demetrakopoulos D, Klepchick PR, Mooar PA. The efficacy of autologous platelet gel in pain control and blood loss in total knee arthroplasty. An analysis of the haemoglobin, narcotic requirement and range of motion. International orthopaedics 2007;31(3):309-13.

27. Khalafi RS, Bradford DW, Wilson MG. Topical application of autologous blood products during surgical closure following a coronary artery bypass graft. European journal of cardio-thoracic surgery : official journal of the European Association for Cardio-thoracic Surgery 2008;34(2):360-4.

28. Akeda K, An HS, Pichika R, Attawia M, Thonar EJ, Lenz ME, Uchida A, Masuda K. Platelet-rich plasma (PRP) stimulates the extracellular matrix metabolism of porcine nucleus pulposus and anulus fibrosus cells cultured in alginate beads. Spine 2006; 31(9):959-66.

29. Xu W, Jong Hong S, Jia S, Zhao Y, Galiano RD, Mustoe TA. Application of a partial-thickness human ex vivo skin culture model in cutaneous wound healing study. Laboratory investigation; a journal of technical methods and pathology 2012;92(4): 584-99.

30. Xu R, Boudreau A, Bissell MJ. Tissue architecture and function: dynamic reciprocity via extra- and intra-cellular matrices. Cancer metastasis reviews 2009;28(1-2):167-76. 